\title{
Meningkatkan Hasil Belajar Siswa pada Materi Perkalian Menggunakan Papan Perkalian
}

\author{
Diterima: \\ 4 Juni 2021 \\ Revisi: \\ 27 Juli 2021 \\ Terbit:
}

1 Februari 2022

\author{
Lailita Nurfi Kurniawati \\ SDN Medowo 1 Kandangan \\ Kediri, Indonesia \\ E-mail: kurnianurfi@gmail.com
}

\begin{abstract}
Abstrak - Berdasarkan hasil observasi yang dilakukan di SDN Medowo 1 oleh peneliti bahwa dalam pembelajaran matematika guru masih menggunakan metode ceramah yang membuat siswa jenuh dan kurang antusias untuk mengikuti kegiatan pembelajaran. Dari 23 siswa yang mengikuti pembelajaran, hanya 26,08\% atau 6 siswa yang hasil belajarnya diatas kriteria ketuntasan minimum yang ditetapkan sekolah. Pelaksanaan pembelajaran melalui penelitian tindakan kelas. Peneliti bertindak sebagai guru yang terlibat langsung dalam proses perencanaan, pelaksanaan, pengamatan, dan refleksi. Pada siklus 1, hasil pengamatan memperlihatkan bahwa kinerja guru sudah baik tetapi masih ada kekurangankekurangan yang harus diperbaiki, keaktifan siswa masih kurang maksimal, dan hasil evaluasi belajar siswa yang mencapai nilai ketuntasan ada 14 anak dengan prosentase ketuntasan klasikal 58,33\%. Siklus 2, hasil pengamatan memperlihatkan kinerja guru sudah baik, kekurangan-kekurangan yang ada pada siklus 1 sudah tidak nampak lagi, siswa aktif dalam mengikuti proses pembelajaran, dan siswa yang mencapai nilai ketuntasan ada 21 anak dengan prosentase klasikal 87,50\%. Ketuntasan belajar meningkat dari $58,33 \%$ menjadi $87,50 \%$. Jadi, dapat disimpulkan bahwa penerapan media papan perkalian pada materi perkalian memberi dampak positif dalam meningkatkan hasil belajar siswa.
\end{abstract}

Kata Kunci - hasil belajar, materi perkalian, papan perkalian

Abstract - Based on the results of observations made at SDN Medowo 1 by researchers that in learning mathematics teachers still use the lecture method which makes students bored and less enthusiastic about participating in learning activities. Of the 23 students who took part in the study, only $26.08 \%$ or 6 students whose learning outcomes were above the minimum completeness criteria set by the school. Implementation of learning through classroom action research. The researcher acts as a teacher who is directly involved in the process of planning, implementing, observing, and reflecting. In cycle 1, the observations showed that the teacher's performance was good but there were still shortcomings that needed to be corrected, student activity was still not optimal, and the results of student learning evaluations who achieved completeness scores were 14 children with a classical completeness percentage of $58.33 \%$. Cycle 2, the observations showed that the teacher's performance was good, the shortcomings in cycle 1 were no longer visible, students were active in following the learning process, and students who achieved completeness scores were 21 children with a classical percentage of $87.50 \%$. Mastery learning increased from $58.33 \%$ to $87.50 \%$. So, it can be concluded that the application of the multiplication board media to the multiplication material has a positive impact on improving student learning outcomes.

Keywords - learning outcomes, multiplication material, multiplication board 
PTK, Vol.2 No.2 2022

ISSN: 2747-1977 (Print) / 2747-1969 (Online)

DOI: https://doi.org/10.53624/ptk.v2i2.52

\section{PENDAHULUAN}

Matematika merupakan salah satu diantara mata pelajaran yang diajarkan di sekolah-sekolah dengan frekuensi jam pelajaran yang lebih banyak dibandingkan dengan mata pelajaran yang lainnya. Namun kenyataannya, pelajaran matematika seringkali dianggap siswa sebagai mata pelajaran yang sulit dan menakutkan. Suasana proses belajar adalah pembelajaran matematika saat ini terasa kaku dan membosankan. Penggunaan media pembelajaran yang tepat akan mempengaruhi hasil belajar dan motivasi siswa dalam proses pembelajaran. Sejumlah hasil penelitian menunjukkan bahwa pengunaan media seperti gambar, ilustrasi, atau model-model kongkret sangat efektif untuk membantu meningkatkan daya ingat seseorang tentang konsep yang sedang dipelajari, terlebih jika media atau peragaan yang digunakan menarik perhatian. Oleh karena itu agar siswa dapat dengan mudah meningat fakta-fakta atau konsep-konsep yang dipelajari, maka guru sangat dianjurkan menggunakan media yang benar-benar sesuai konsep yang dibahas serta menarik perhatian siswa.

Minimnya sarana dan prasarana yan ada pada SDN Medowo 1 menjadi salah satu penyebab dari guru untuk menggunakan media pembelajaran. Padahal, penggunaan media pembelajaran tidak harus dibuat secara khusus. Banyak hal-hal atau benda-benda di kehidupan nyata dapat dijadikan media pembelajaran, khususnya pembelajaran matematika. Hak itu selain mempermudah guru, juga dapat mengaitkan imajinasi siswa kedalam pembelajaran matematika.

Dalam permasalahan tersebut, peneliti tertarik dan merasa perlu untuk memecahkan masalah tersebut dengan melakukan penelitian menggunakan ,media papan perkalian pada materi perkalian. Hal ini dimaksudkan untuk dapat memberikan model yang kongkret tentang operasi hitung perkalian yang dapat digunakan dalam kehidupan sehari-hari.

Penggunaan media papan perkalian merupakan inovasi baru yang menarik agar dapat meningkatkan hasil belajar siswa. Siswa dapat aktif dalam proses pembelajaran, siswa dengan bebas mengkomunikasikan ide-idenya satu sama lain. Guru membantu membandingkan ide-ide tersebut dan membimbing siswa mengambil keputusan tentang ide terbaik mereka (Afandi et al. 2013).

Peneliti tertarik dan merasa perlu untuk memecahkan masalah tersebut yaitu dengan mengunakan media pembelajaran yang bertujuan untuk meningkatkan hasil belajar siswa pada materi perkalian. Untuk mewujudkan pembelajaran yang bermakna dan menyenangkan maka dibutuhkan sebuah media pembelajaran yang menarik dan bervariasi. Seorang guru hendaknya mampu memberikan pembelajaran yang baik dan mudah dipahami oleh. Salah satu upaya yang 
dapat dilakukan untuk merancang pembelajaran matematika yang menyenangkan yaitu menggunakan media media papan perkalian dalam materi perkalian.

Belajar adalah suatu proses usaha yang dilakukan seseorang untuk memperoleh suatu perubahan. Menurut Gagne (Suprijono 2009) perubahan yang dilakukan merupakan perubahan disposisi atau kemampuan yang dicapai seseorang melalui aktivitas. Perubahan disposisi tersebut bukan diperoleh langsung dari proses pertumbuhan seseorang secara ilmiah. Sedangkan Travers mengemukakan bahwa belajar adalah proses menghasilkan penyesuaian tingkah laku (Suprijono 2009). Menurut Morgan (Suprijono 2009), belajar adalah perubahan perilaku yang bersifat permanen sebagai hasil dari pengalaman. Oleh karena itu, seseorang dikatakan belajar bila diasumsikan dalam diri orang itu terjadi perubahan suatu proses kegiatan yang mengakibatkan suaru perubahan tingkah laku. Perubahan tingkah laku itu memang dapat diamati dalam kurun waktu yang relatif lama disertai usaha orang tersebut berubah dari tidak mampu mengerjakan sesuatu menjadi mampu mengerjakan sesuatu.

Belajar adalah suatu proses perubahan tingkah laku akibat dari pengalaman (Darmuki 2020). Belajar merupakan suatu proses perubahan tingkah laku yang membutuhkan dorongan atau motivasi untuk menggerakkan ke arah lebih baik, dari tidak bisa menjadi bisa, dari tidak tahu menjadi tahu (Darmuki et al. 2017). Perubahan tingkah laku tersebut bisa berupa dari aspek kognitif, afektif, maupun psikomotorik (Hidayati et al. 2020). Belajar juga dapat didefinisikan sebuah proses dimana tingkah laku ditimbulkan/berubah melalui latihan dan pengalaman (Darmuki and Hariyadi 2019). Mengajar adalah menanamkan pengetahuan pada peserta didik untuk mencapai tujuan yang telah ditetapkan (Hidayati 2020). Kegiatan Belajar Mengajar (KBM) adalah suatu proses interaksi antara peserta didik dengan pendidik dan sumber belajar pada suatu lingkungan belajar (Hidayati et al. 2020).

Ada beberapa pendapat tentang belajar matematika seperti yang dikemukakan Menurut Robert Gagne, belajar matematika harus didasarkan kepada pendangan bahwa tahap belajar yang lebih tinggi berdasarkan tahap belajar yang lebih rendah. (2) menurut J. Bruner, belajar matematika adalah belajar tentang konsep-konsep dan strujtur matematika yang terdapat dalam materi yang dipelajari serta mencari hubungan antara konsep-konsep dan struktur-struktur matematika. (3) Z.P Dienes berpendapat bahwa setiap konsep atau prinsip matematika dapat dimengerti secara sempurna hanya jika pertama-tama disajikan kepada siswa dalam bentuk konkret (Suprijono 2009).

Kemudian menurut Sudjana \& Rivai (2015), menyebutkan bahwa media pembelajaran dalam proses belajar bermanfaat agar: (1) pembelajaran lebih menarik perhatian sehingga menumbuhkan motivasi belajar siswa, (2) materi pembelajaran akan lebih mudah dipahami oleh siswa, (3) metode mengajar menjadi lebih variatif sehingga dapat mengurangi kebosanan PTK: Jurnal Tindakan Kelas | Hal:113-119 
PTK, Vol.2 No.2 2022

ISSN: 2747-1977 (Print) / 2747-1969 (Online)

DOI: https://doi.org/10.53624/ptk.v2i2.52

belajar, (4) siswa lebih aktif melakukan kegiatan belajar. Adapun kegunaan media pembelajaran sebagai berikut: (1) memperjelas penyajian pesan, (2) mengatasi keterbatasan ruang, waktu, dan daya indera, (3) mengatasi sikap pasif, sehingga peserta didik menjadi lebih semangat dan lebih mandiri dalam belajar, (4) memberikan rangsangan, pengalaman, dan persepsi yang sama terhadap materi belajar (Sadiman 2006).

Dari hal di atas, media yang difokuskan untuk dijadikan solusi adalah media Papan perkalian. Dalam media papan perkalian siswa akan lebih mudah dalam menemukan konsepkonsep dalam proses pembelajaran khususnya materi perkalian. Pembelajaran dengan menggunakan media papan perkalian dapat melatih anak berpikir cepat dan lebih mudah dalam memahami konsep perkalian, siswa lebih antusias untuk mengikuti pembelajaran sihingga bisa meningkatkan hasil belajar siswa pada materi perkalian.

Berdasarkan uraian latar belakang tersebut, peneliti akan melakukan penelitian dengan judul "Meningkatkan Hasil Belajar Siswa Pada Materi Perkalian Dengan Menggunakan Papan Perkalian Siswa Kelas III SDN Medowo 1 Kecamatan Kandangan Kabupaten Kediri”. Berdasarkan judul tersebut dirumuskan tujuan penelitian tindakan ini adalah untuk menjelaskan peningkatan kemampuan hasil belajar siswa melalui media papan perkalian pada siswa kelas III SDN Medowo 1 Kecamatan Kandangan Kabupaten Kediri.

\section{METODE}

Jenis penelitian ini adalah Penelitian tindakan Kelas (PTK) dengan menggunakan design penelitian model Kemmis dan Taggart, 1998 (Rochiati 2005).

\section{Gambar 1 Siklus PTK}

Penelitian ini dilaksanakan pada semester ganjil Tahun Pelajaran 2019/2020, yaitu pada bulan tanggal 1 Agustus 2019 sampai 31 Agustus 2019. Subjek penelitian ini adalah peserta didik kelas III SDN Medowo 1 yang terdiri dari 24 siswa. Objek penelitian adalah hasil belajar siswa. 
Teknik pengumpulan data menggunakan observasi, hasil tes evaluasi siswa. Data dianalisis secara deskriptif dan disajikan dalam bentuk tabel dan grafik.

\section{HASIL DAN PEMBAHASAN}

Berdasarkan pelaksanaan tindakan selama 2 siklus yang dilakukan sebanyak 4 kali pertemuan, diperoleh data bahwa hasil belajar siswa mengalami peningkatan. Peningkatan hasil belajar diketahui dengan penggunaan media papan perkalian. Hasil evaluasi terhadap penerapan penggunaan media papan perkalian dapat dilihat pada diagram berikut.

Tabel 1. Hasil Belajar Siswa pada Materi Keliling Bangun Datar

\begin{tabular}{ccc}
\hline Jumlah siswa & Keterangan & Prosentase \\
\hline 6 & Tuntas & $25,00 \%$ \\
\hline 18 & Tidak Tuntas & $75,00 \%$ \\
\hline
\end{tabular}

Tabel 2. Hasil Belajar Siswa pada Materi Keliling Bangun Datar

\begin{tabular}{ccc}
\hline Jumlah siswa & Keterangan & Prosentase \\
\hline 14 & Tuntas & $58,33 \%$ \\
\hline 10 & Tidak Tuntas & $41,67 \%$ \\
\hline
\end{tabular}

Tabel 3. Hasil Belajar Siswa pada Materi Keliling Bangun Datar

\begin{tabular}{ccc}
\hline Jumlah siswa & Keterangan & Prosentase \\
\hline 18 & Tuntas & $75,00 \%$ \\
\hline 6 & Tidak Tuntas & $35,00 \%$ \\
\hline
\end{tabular}

Tabel 4. Hasil Belajar Siswa pada Materi Keliling Bangun Datar

\begin{tabular}{ccc}
\hline Jumlah siswa & Keterangan & Prosentase \\
\hline 21 & Tuntas & $87,5 \%$ \\
\hline 3 & Tidak Tuntas & $12,5 \%$ \\
\hline
\end{tabular}

Dari hasil evaluasi yang dicapai siswa seperti terlihat pada tabel 1,2, 3 dan 4 terlihat adanya peningkatan hasil belajar siswa. Pada pertemuan 1 (siklus 1) sebelum menggunakan media papan perkalian, prosentase ketuntasan siswa 25\%. Hal ini menunjukkan masih rendahnya pemahaman siswa terhadap materi yang disampaikan guru. Pada pertemuan 2 prosentase mulai naik menjadi 58,33\%, pada pertemuan 3 (siklus 2) prosentase ketuntasan mencapai $75 \%$, dan pada pertemuan 4 prosentase ketuntasan mencapai 87,5\%. Dari 4 proses evaluasi yang sudah dilalui, terlihat bahwa pada pertemuan 1 sampai 4 terlihat adanya kenaikan hasil belajar siswa. Pada pertemuan 2 mengalami peningkatan 33,33\%, pada pertemuan 3 kembali mengalami peningkatan $16,67 \%$. Terakhir pada pertemuan ke 4 juga mengalami peningkatan yaitu $12,5 \%$. 
PTK, Vol.2 No.2 2022

ISSN: 2747-1977 (Print) / 2747-1969 (Online)

DOI: https://doi.org/10.53624/ptk.v2i2.52

Penggunaan media papan perkalian dalam pembelajaran matematika materi perkalian menjadi lebih bermakna menyenangkan, dan siswa dapat berperan aktif dalam proses pembelajaran. Siswa dapat menemukan konsep perkalian dengan penggunaan media tersebut. Aktivitas yang dilakukan siswa dalam pembelajaran dapat membuat pembelajaran lebih bermakna dan menyenangkan sehingga konsep perkalian dapat dengan mudah diingat oleh siswa. Hal ini ini di dukung oleh pendapat Asnawir dan Usman (2002) yang menyatakan bahwa media belajar (1) Membantu memudahkan belajar bagi siswa dan membantu memudahkan mengajar bagi guru, (2) Memberikan pengalaman lebih nyata (yang abstrak dapat menjadi lebih konkrit), (3) Menarik perhatian siswa lebih besar (kegiatan pembelajaran dapat berjalan lebih menyenangkan dan tidak membosankan), (4) Semua indra siswa dapat diaktifkan. (5) Lebih menarik perhatian dan minat murid dalam belajar.

Bila ditinjau dari hasil evaluasi siswa, hasil belajar siswa dalam materi perkalian mengalami peningkatan pada setiap siklusnya. Pada siklus I pertemuan 2 hasil belajar siswa meningkat sebesar 33,33\%. Pada siklus 2 pertemuan 3 hasil belajar siswa meningkat sebesar 16,67\% dan pada siklus 2 pertemuan 4 hasil belajar siswa meningkat sebesar 12,5\%.

\section{KESIMPULAN}

Berdasarkan hasil dan pembahasan di atas, dapat disimpulkan bahwa, media papan perkalian dapat meningkatkan hasil belajar siswa pada materi perkalian. Melalui media papan perkalian siswa dapat lebih terstimulus untuk menemukan konsep-konsep perkalian sehingga siswa lebih mudah untuk mengingat materi tersebut. Melalui media papan perkalian, siswa dapat lebih aktif dalam mengikuti pembelajaran, dapat menarik motivasi siswa sehingga siswa bisa lebih antusian untuk mengikuti kegiatan pembelajaran sehingga bisa meningkatkan hasil belajar siswa. Selain itu, peneliti memberikan saran bagi pihak sekolah hendaknya memfasilitasi guru dengan media pembelajaran yang modern, mengadakan sharring antar sesama guru tentang media pembelajaran yang dapat mendukung proses pembelajaran. Saran bagi guru, hendaknya pada saat pembelajaran di kelas guru dapat meminimalkan penggunaan metode ceramah, mengembangkan pelaksanaan pembelajaran dengan inovasi pendidikan seperti menciptakan media pembelajaran yang inovatif. 


\section{DAFTAR PUSTAKA}

Afandi, Muhamad, Evi Chamalah, Oktarina Puspita Wardani, and H. Gunarto. 2013. "Model Dan Metode Pembelajaran." Semarang: Unissula.

Asnawir \& Usman, B. 2002. Media Pembelajaran. Jakarta: Ciputat

Darmuki, Agus. 2020. Upaya Meningkatkan Kemampuan Berbicara Mahasiswa Menggunakan Media Aplikasi Google Meet Berbasis Unggah Tugas Video Di Youtube Pada Masa Pandemi Covid-19. Jurnal Educatio FKIP UNMA, Vol 6(2),655-661.

Darmuki, A. \& Hariyadi, A. 2019. Eksperimentasi Model Pembelajaran Jucama Ditinjau Dari Gaya Belajar Terhadap Prestasi Belajar Mahasiswa Mata Kuliah Berbicara Di Prodi PBSI IKIP PGRI Bojonegoro. Kredo. 3(1), 62-72.

Darmuki, A., Hariyadi, A., Hidayati, N. A. 2020. Peningkatan Minat dan Hasil Belajar Keterampilan Berbicara Menggunakan Metode Mind Map pada Mahasiswa Kelas IA PBSI IKIP PGRI Bojonegoro Tahun Akademik 2019/2020. Kredo.

Hidayati, N. A. 2020. Penerapan Metode Mind Map Berbasis Drill Untuk Meningkatkan Kemampuan Berbicara Mahasiswa di Prodi PBSI IKIP PGRI Bojonegoro . Jurnal Educatio FKIP UNMA, 6(2), 462-468.

Hidayati, N. A., Waluyo, H. J., Winarni, R., \& Suyitno. 2020. Exploring the Implementation of Local Wisdom-Based Character Education among Indonesian Higher Education Students. International Journal of Instruction, 13(2), 179-198. https://doi.org/10.29333/iji.2020.13213a

Rochiati, W. 2015. Metode Penelitian Tindakan Kelas. Bandung: P.T. Remaja Rosdakarya.

Sadiman, A.S. (2006). Media pendidikan: Pengertian, pengembangan dan pemanfaatannya. Jakarta: PT Raja Grafindo Persada

Sudjana, N, Rivai, A 2015. Media Pengajaran. Cetakan ke-12. Bandung: Sinar. Baru Algensindo

Suprijono, Agus. 2009. Cooperative Learning: Teori dan Aplikasi Paikem. Yogyakarta: Pustaka Pelajar. 